\title{
Therapeutic Advantage of Converting Enzyme Inhibitors in Arresting Progressive Renal Disease Associated with Systemic Hypertension in the Rat
}

\author{
Sharon Anderson, Helmut G. Rennke, and Barry M. Brenner \\ With the technical assistance of J. L. Troy, J. L. Noddin, A. W. Nunn, S. L. Riley, and D. Sandstrom \\ Laboratory of Kidney and Electrolyte Physiology, Departments of Medicine and Pathology, Brigham and Women's Hospital and \\ Harvard Medical School, Boston, Massachusetts 02115
}

\begin{abstract}
Micropuncture and morphologic studies were performed in six groups of male Munich-Wistar rats after removal of the right kidney and segmental infarction of two-thirds of the left kidney. Groups 1 and 4 received no specific therapy. Groups 2 and 5 were treated with the angiotensin I-converting enzyme inhibitor, enalapril, $50 \mathrm{mg} / \mathrm{liter}$, in the drinking water. Groups 3 and 6 were treated with reserpine $(5 \mathrm{mg} / \mathrm{liter})$, hydralazine $(80 \mathrm{mg} /$ liter), and hydrochlorothiazide ( $25 \mathrm{mg} / \mathrm{liter})$. All rats were fed standard chow. Groups 1-3 underwent micropuncture study 4 wk after renal ablation. Untreated group 1 rats exhibited systemic hypertension and elevation of the single nephron glomerular filtration rate (SNGFR) due to high average values for the mean glomerular transcapillary hydraulic pressure gradient $(\overline{\Delta \mathbf{P}})$ and glomerular plasma flow rate $\left(Q_{A}\right)$. In group 2 rats, treatment with enalapril prevented systemic hypertension and maintained $\overline{\Delta \mathbf{P}}$ at near-normal levels without significant reduction in SNGFR and $Q_{\mathrm{A}}$. In contrast, triple drug therapy normalized systemic hypertension, but failed to lower $\overline{\Delta \mathbf{P}}$ in group 3 rats. Groups $4-$ 6 were followed for 12 wk after renal ablation. Untreated group 4 rats demonstrated continuous systemic hypertension, progressive proteinuria, and glomerular structural lesions, including mesangial expansion and frequent areas of segmental sclerosis. In group 5 rats, treatment with enalapril maintained systemic blood pressure at normal levels over the 12-wk period and dramatically limited the development of proteinuria and glomerular lesions. Despite equivalent systemic blood pressure control in group 6 rats, failure of triple drug therapy to control glomerular hypertension was associated with progressive proteinuria and glomerular lesions comparable to those seen in untreated group 4 rats. Thus, unless glomerular capillary hypertension is corrected, control of systemic blood pressure is insufficient to prevent progressive renal injury in rats with reduced renal mass.
\end{abstract}

\section{Introduction}

Reduction of renal mass leads to structural and functional hypertrophy, with marked increases in the perfusion and filtration

Portions of these studies were presented at the 18th Annual Meeting of the American Society of Nephrology, New Orleans, LA, 17 Dec. 1985, and published in abstract form, 1986. Kidney Int. 29:314A.

Address reprint requests to Dr. Anderson, Renal Division, Brigham \& Women's Hospital, 75 Francis St., Boston, MA 02115.

Received for publication 2 October 1985 and in revised form 29 January 1986.

J. Clin. Invest.

(c) The American Society for Clinical Investigation, Inc. 0021-9738/86/06/1993/08 \$1.00

Volume 77, June 1986, 1993-2000 of the remaining nephron units (1-3). Hyperfiltration in these nephrons results from elevations in the mean glomerular transcapillary hydraulic pressure gradient $(\overline{\Delta \mathrm{P}})^{1}$ and plasma flow rate $\left(Q_{\mathrm{A}}\right)$. In the remnant kidneys of rats subjected to extensive renal ablation, these elevated glomerular capillary pressures and flows are associated with progressive proteinuria and eventual glomerular sclerosis $(3,4)$.

Therapeutic interventions which attenuate these adaptive glomerular hemodynamic changes slow the development of glomerular structural injury. Dietary protein restriction, which lowers the single nephron (SN) glomerular filtration rate (GFR) by normalizing glomerular capillary pressures and flows, retards the development of glomerular sclerosis in the hyperfiltering kidneys of rats with reduced renal mass (5), diabetes mellitus (6), and mineralocorticoid-induced hypertension (7). Alternatively, selective reduction of $\overline{\Delta P}$ with the angiotensin I (AI)converting enzyme inhibitor enalapril lessens glomerular injury in rats with reduced renal mass (4) or experimental diabetes (8). Central to each of these therapies is normalization of $\overline{\Delta \mathrm{P}}$, since enalapril therapy induces no significant change in $Q_{\mathrm{A}}$ or in SNGFR $(4,8)$.

Systemic hypertension, when transmitted to the glomerular capillary network, results in glomerular capillary hypertension. Elevated systemic pressures are accompanied by elevated glomerular capillary pressures in several experimental models of hypertensive renal disease, including renal ablation $(3,4)$, postsalt hypertension (9), and chronic mineralocorticoid administration (7). While the foregoing enalapril studies suggest that systemic blood pressure therapy resulting in normalization of $\overline{\Delta \mathrm{P}}$ protects against eventual glomerular injury, it remains unclear whether other antihypertensive regimens would be equally protective. In 1976, Purkerson and co-workers reported that normalization of systemic blood pressure in remnant kidney rats treated with reserpine, hydralazine, and hydrochlorothiazide afforded only modest protection against glomerular structural injury (10). Recent reports suggest that a similar regimen confers protection in certain models of hypertensive renal disease (11, 12), but fails to protect against glomerular injury in others $(13,14)$.

In designing the present study, we reasoned that systemic hypertension must be transmitted to the glomerular capillary network in order for glomerular structural injury to eventuate. Consequently, reduction in systemic pressure must result in re-

1. Abbreviations used in this paper. $\mathrm{AI}$, angiotensin $\mathrm{I} ; \overline{\mathrm{AP}}$, mean arterial pressure under anesthesia; GFR, glomerular filtration rate; Hct, hematocrit; $K_{\mathrm{f}}$, glomerular capillary ultrafiltration coefficient; $\overline{\Delta \mathrm{P}}$, mean glomerular transcapillary hydraulic pressure difference; $\bar{P}_{\mathrm{GC}}$, mean glomerular capillary hydraulic pressure; $Q_{\mathrm{A}}$, glomerular capillary plasma flow rate; $\mathrm{SN}$, single nephron; SNGFR, single nephron glomerular filtration rate. 
duction in glomerular capillary pressure in order to confer protection upon glomeruli at risk for eventual sclerosis. We further reasoned that a conventional triple drug regimen, containing both vasodilators and a diuretic, might be a potent stimulus to the renin-angiotensin system, and accordingly, cause efferent arteriolar vasoconstriction sufficient to maintain the high glomerular capillary pressures seen in untreated rats with reduced renal mass. Accordingly, we compared the glomerular hemodynamic and morphologic effects of systemic blood pressure control with reserpine, hydralazine, and hydrochlorothiazide with those in untreated remnant kidney rats, and with those seen in rats treated with enalapril.

\section{Methods}

Six groups of male Munich-Wistar rats with initial weights of 220-250 $\mathrm{g}$ were used in these studies. All rats were subjected to five-sixths renal ablation by removal of the right kidney and infarction of approximately two-thirds of the left kidney by ligation of two or three branches of the left renal artery. All groups were fed standard rat chow (Wayne Rodent Blox, Allied Mills, Chicago, IL) containing $\sim 24 \%$ protein by weight.

Groups 1 and 4 received no specific therapy. Groups 2 and 5 were treated with the AI-converting enzyme inhibitor, enalapril (Merck, Sharp \& Dohme, West Point, PA), at a dose of $50 \mathrm{mg} /$ liter in the drinking water starting $1 \mathrm{wk}$ after ablation. Groups 3 and 6 received reserpine ( 5 $\mathrm{mg} /$ liter), hydralazine $(80 \mathrm{mg} / \mathrm{liter})$, and hydrochlorothiazide $(25 \mathrm{mg} /$ liter) (Sigma Chemical Co., St. Louis, MO) in the drinking water starting 1 wk after ablation. Pilot studies established that all three drugs were necessary to control systemic blood pressure at levels comparable to those achieved with enalapril. Groups 1-3 (each $n=8$ ) underwent micropuncture study 4 wk after ablation. Groups 4-6 (each $n=12$ ) were followed for 12 wk after ablation, at which time the remnant kidneys were perfusion-fixed for evaluation of structural damage.

Systolic blood pressure was measured weekly in all rats, in the conscious state, by the tail cuff method (15). 24-h urinary total protein excretion was measured in groups 4-6 at 3,6,9, and 12 wk after ablation. Plasma renin concentrations were measured in separate groups of shamoperated rats, and in rats with five-sixths nephrectomy receiving either no treatment, enalapril, or reserpine, hydralazine, and hydrochlorothiazide (each $n=7$ ). Rats were decapitated and trunk blood collected in EDTA 4 wk after operation.

Micropuncture studies. For micropuncture study, rats were anesthetized with Inactin $(100 \mathrm{mg} / \mathrm{kg}$ body wt, i.p.) and placed on a temperature-regulated micropuncture table. Immediately after the induction of anesthesia, the left femoral artery was catheterized with PE-50 polyethylene tubing, followed by a baseline collection of $210 \mu \mathrm{l}$ of arterial blood. This arterial catheter was used for subsequent periodic blood sampling and estimation of mean arterial pressure $(\overline{\mathrm{AP}}) . \overline{\mathrm{AP}}$ was monitored with an electronic transducer (model P23Db; Statham Instruments Div., Gould Inc., Oxnard, CA) connected to a direct-writing recorder (model 7702B; Hewlett-Packard Co., Palo Alto, CA). Polyethylene catheters were also inserted into the left and right jugular veins for infusions of inulin and plasma. Intravenous infusions of isoncotic rat plasma and $4 \%$ inulin solution in $0.9 \% \mathrm{NaCl}$ were started at rates of 6.0 and $1.2 \mathrm{ml}$ / $h$, respectively. The left kidney was exposed by a subcostal incision and separated from the adrenal gland and the surrounding perirenal fat. The left kidney was suspended on a lucite holder, and its surface illuminated with a fiberoptic light source and bathed with isotonic $\mathrm{NaCl}$.

Since the plasma volume of rats prepared for micropuncture is reduced by $\sim 20 \%$ (16), the following protocol for maintaining the euvolemic state was employed. After insertion of the jugular catheters, isoncotic rat plasma was infused for $\sim 25 \mathrm{~min}$, in a total amount equal to $1 \%$ of body weight, followed by a reduction in infusion rate to $0.41 \mathrm{ml} / \mathrm{h}$ for the remainder of the experiment to maintain the baseline hematocrit (Hct) at the value determined immediately after induction of anesthesia.

Micropuncture measurements were carried out as follows. Exactly timed (1-1.5 min) samples of tubule fluid were collected from surface convolutions of four nephrons for determination of flow rate and inulin concentration and calculation of SNGFR. The majority of tubules are morphologically normal at this time point, and the few collapsed tubules were avoided. Six to eight samples of efferent arteriolar blood were obtained for determination of protein concentration. Coincident with these sample collections, $140 \mu \mathrm{l}$ of femoral arterial blood were obtained in each period for determination of Hct and plasma concentrations of protein and inulin, and 15-20-min urine collections were obtained for determination of flow rate and inulin concentration. Time-averaged hydraulic pressures were measured in accessible surface glomerular capillaries (average, 2-4), 6-8 proximal tubules, and 6-8 efferent arterioles with a continuous recording, servo-null micropipette transducer system (model 3; Instrumentation for Physiology and Medicine, San Diego, CA). Hydraulic output from the servo system was coupled electronically to a second channel of the Hewlett-Packard recorder by means of a pressure transducer. Colloid osmotic pressure of plasma entering and leaving glomerular capillaries was estimated from values for protein concentration in femoral arterial and surface efferent arteriolar plasma samples using the equation derived by Deen et al. (17). Values for protein concentration, and thus colloid osmotic pressure, for femoral arterial plasma are taken as representative of values for these parameters for the afferent end of the glomerular capillary network. These estimates of preglomerular and postglomerular plasma protein concentration permit calculation of single nephron filtration fraction, glomerular capillary ultrafiltration coefficient $\left(K_{f}\right)$, glomerular and postglomerular blood flow rates, and single afferent and efferent arteriolar resistances, using equations previously described (17).

Morphology. Rats in groups 4-6, followed for 12 wk after ablation, were processed for morphologic examination. Kidneys were fixed by perfusion at the measured arterial pressure with $1.25 \%$ glutaraldehyde in $0.1 \mathrm{M}$ cacodylate buffer ( $\mathrm{pH}$ 7.4). After perfusion-fixation, one or two 3-4 mm thick coronal sections through the mid-portion of the remnant were postfixed in $4 \mathrm{~g} / 100 \mathrm{ml}$ buffered formaldehyde solution and proc essed for light microscopy through paraffin embedding. Sections $3-\mu \mathrm{m}$ thick were stained with hematoxylin/eosin and by the periodic acidSchiff technique. Random fragments of cortical tissue were postfixed in $1 \%$ aqueous osmium tetroxide and embedded in epoxy resin. $1-\mu \mathrm{m}$ thick plastic sections were stained with toluidine blue and examined by light microscopy. The frequency of focal and segmental glomerular lesions was determined by examining all glomerular profiles (average, 206 profiles per animal) contained in one or two coronal sections from each animal. Segmental lesions were specifically defined as areas of the tuft showing collapse of the glomerular capillaries, often accompanied by hyaline deposition and/or adhesion of the tuft to Bowman's capsule. For each animal, the number of glomeruli with segmental lesions was expressed as a percentage of the total number of glomeruli counted. Other glomerular changes, such as expansion of the mesangial areas and abnormalities of tubules, interstitium, arteries, and arterioles, were assessed nonquantitatively by light microscopy.

Analytical. The volume of fluid collected from individual proximal tubules was estimated from the length of the fluid column in a constant bore capillary tube of known internal diameter. The concentration of inulin in tubule fluid was measured, usually in duplicate, by the microfluorescence method of Vurek and Pegram (18). Inulin concentrations in plasma and urine were determined by the macro-anthrone method of Führ et al. (19). Protein concentrations in efferent arteriolar and femoral arterial blood plasmas were determined, usually in duplicate, using the fluorometric method developed by Viets et al. (20). Plasma urea nitrogen concentration was measured using a Beckman Analyzer 2 (Beckman Instruments Inc., Fullerton, CA). Urinary total protein concentration was measured by precipitation with $3 \%$ sulfosalicylic acid (21). Urinary sodium concentration was determined by flame photometry. Plasma renin concentration was determined by incubating $100 \mu$ l of rat plasma with $100 \mu \mathrm{l}$ rat anephric plasma and $400 \mu \mathrm{l}$ of $0.2 \mathrm{M}$ maleate buffer, $\mathrm{pH}$ 6.0 at $37^{\circ}$ for $1 \mathrm{~h}$. Appropriate dilutions of rat plasma samples were made using Tris buffer. The generation of AI was then determined by radioimmunoassay using commercially available reagents (New England Nuclear, Boston, MA). 
Statistical. Statistical analysis was performed by one-way analysis of variance followed by computation of modified $t$ values and multiple pairwise comparisons according to the method of Bonferroni (22). Nonparametric rank testing using the Kruskal-Wallis test statistic was performed for plasma renin concentration values (23). Statistical significance was defined as $P<0.05$.

\section{Results}

Systemic blood pressure. In untreated rats, removal of five-sixths of the renal mass resulted in the prompt development of systemic hypertension within $2 \mathrm{wk}$ after ablation. As demonstrated in Fig. 1, systolic blood pressure in group 4 rats averaged $177 \pm 7$ (SEM) $\mathrm{mmHg}$ by the second week after ablation, and hypertension was sustained or tended to increase during the final weeks of the observation period. Despite equally extensive renal ablation, the development of systemic hypertension was prevented in rats treated with either enalapril or with triple drug therapy. Systolic blood pressure values were comparable in groups 5 and 6 , and were controlled to levels within the normal range.

Micropuncture studies. Mean values for body weight, Hct, plasma urea nitrogen concentration, whole kidney GFR, $\overline{\mathrm{AP}}$, SNGFR, and the pressures, flows, and resistances governing glomerular ultrafiltration for groups 1-3 are summarized in Table I. Treatment with triple drug therapy, but not with enalapril, resulted in slightly lower values for body weight $(P<0.01)$ and Hct $(P<0.01)$ as compared with untreated group 1 rats. Mean $\overline{\mathrm{AP}}$ under anesthesia was markedly elevated in untreated group 1 rats, averaging $154 \pm 8 \mathrm{mmHg}$, whereas hypertension was absent in groups $2(107 \pm 2 \mathrm{mmHg})$ and $3(107 \pm 3 \mathrm{mmHg})$ (both $P$ $<0.005$ vs. group 1). Despite the lower renal perfusion pressure in the treated groups, values for remnant kidney GFR did not differ significantly among the three groups, averaging $0.60 \pm 0.07$ $\mathrm{ml} / \mathrm{min}$ in group $1,0.54 \pm 0.05 \mathrm{ml} / \mathrm{min}$ in group 2 , and $0.61 \pm 0.08$ $\mathrm{ml} / \mathrm{min}$ in group 3 (NS). All three groups of rats were azotemic, with values for plasma urea nitrogen concentration averaging $56 \pm 6 \mathrm{mg} / 100 \mathrm{ml}$ in group $1,55 \pm 3 \mathrm{mg} / 100 \mathrm{ml}$ in group 2 , and $60 \pm 4 \mathrm{mg} / 100 \mathrm{ml}$ in group 3 (NS).

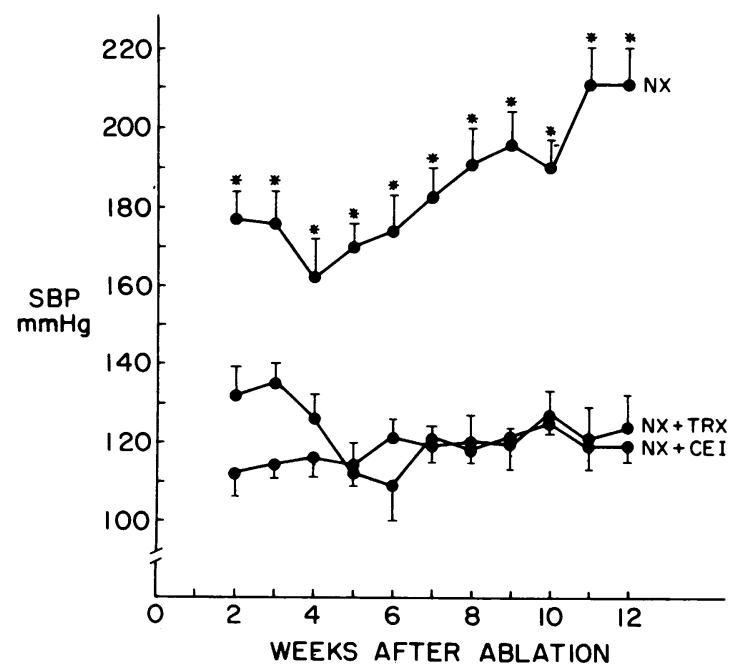

Figure 1. Systolic blood pressure. Systolic blood pressure (SBP) measured by the tail cuff method in conscious rats followed for $12 \mathrm{wk}$ after five-sixths nephrectomy. Untreated rats (group 4, NX) exhibited sustained systemic hypertension, while enalapril treatment (group 5 , $\mathrm{NX}+\mathrm{CEI}$ ), and triple drug treatment (group 6, NX + TRX) maintained systemic blood pressure at normal levels. Values are means \pm SEM. ${ }^{*} P<0.01$ vs. groups 5 and 6 at the same time point.
Single nephron hyperfiltration was evident in all three groups, with values for SNGFR averaging $73.0 \pm 6.0 \mathrm{nl} / \mathrm{min}$ in group 1 , $66.0 \pm 4.1 \mathrm{nl} / \mathrm{min}$ in group 2, and $63.6 \pm 5.2 \mathrm{nl} / \mathrm{min}$ in group 3 (NS). Neither antihypertensive regimen resulted in a significant change in SNGFR as compared with untreated group 1 rats. In the untreated group 1 rats, in accord with previous hemodynamic studies of rats with renal ablation (2-4), hyperfiltration in the remnant nephrons could be attributed to two factors. First, $Q_{\mathrm{A}}$ was elevated on average to $234 \pm 16 \mathrm{nl} / \mathrm{min}$, due to marked reductions in afferent and efferent arteriolar resistances. Second, $\overline{\Delta \mathrm{P}}$ averaged $50 \pm 2 \mathrm{mmHg}$, a value considerably higher than that seen in normal rats (24). This high average value for $\overline{\Delta P}$ resulted despite a slight elevation of proximal tubule hydraulic pressure because of more marked elevation of the mean glomerular capillary hydraulic pressure, $\bar{P}_{\mathrm{GC}}$, which averaged $68 \pm 2$ $\mathrm{mmHg}$ in the remnant glomeruli (Table I). Values for proximal tubule and efferent arteriolar hydraulic pressures were not different among the three groups.

Despite comparable reduction in renal mass, and equivalent control of systemic arterial blood pressure, the rats treated with enalapril and with triple drug therapy exhibited strikingly different glomerular hemodynamic patterns from one another as well as from the untreated group 1 rats. In accord with our previous study of enalapril therapy in rats with reduced renal mass (4), control of systemic blood pressure in enalapril-treated group 2 rats was associated with prevention of glomerular capillary hypertension, so that $\bar{P}_{\mathrm{GC}}(53 \pm 1 \mathrm{mmHg})$ and therefore $\overline{\Delta \mathrm{P}}(36 \pm 1$ $\mathrm{mmHg}$ ) remained at levels near those seen in intact, two-kidney rats (24). SN hyperfiltration in these group 2 rats was therefore maintained primarily by the elevated $Q_{\mathrm{A}}$, but also by a significant increment in $K_{\mathrm{f}}$. Because all animals were in filtration pressure disequilibrium, with values for $\overline{\Delta \mathrm{P}}$ greater than efferent arteriolar oncotic pressure, unique values for $K_{\mathrm{f}}$ were calculable. In enalapril-treated group 2 rats, $K_{\mathrm{f}}$ averaged $0.0965 \pm 0.0133 \mathrm{nl} /$ $(\mathrm{s} \cdot \mathrm{mmHg})$, a value significantly higher than that observed in untreated group 1 rats $(0.0492 \pm 0.0051 \mathrm{nl} /[\mathrm{s} \cdot \mathrm{mmHg}])(P$ $<0.005$ ). Maintenance of the high glomerular plasma flow rate in these rats reflected marked arteriolar vasodilatation, with a significant reduction in afferent, efferent, and total arteriolar resistances. Presumably, reduction in efferent arteriolar resistance resulted in reduction of $\bar{P}_{\mathrm{GC}}$ and therefore $\overline{\Delta \mathrm{P}}$ in this group. Values for afferent and efferent arteriolar plasma protein concentration and colloid osmotic pressure did not differ from the untreated group 1 animals.

Triple drug therapy with reserpine, hydralazine, and hydrochlorothiazide in group 3 rats resulted in control of systemic blood pressure comparable to that seen in the enalapril-treated group 2 rats, but the effects on glomerular hemodynamics were strikingly different. In groups 2 and 3, reduction of systemic blood pressure resulted in a significant reduction in afferent arteriolar resistance (Table I), possibly due to autoregulation. However, efferent arteriolar resistance was not different from that seen in the untreated group 1 rats. Accordingly, glomerular capillary hydraulic pressure remained at levels comparable to those seen in untreated group 1 rats. In group 3 rats, SN hyperfiltration was due to elevations of $Q_{\mathrm{A}}$ and $\overline{\Delta \mathrm{P}}$, a pattern similar to that seen in the untreated group 1 rats. In these rats treated with triple drug therapy, in marked contrast to the enalapriltreated rats, control of systemic blood pressure was not associated with reduction in $\bar{P}_{\mathrm{GC}}$ or $\overline{\Delta \mathrm{P}}$, or elevation of $K_{\mathrm{f}}$.

Activity of the renin-angiotensin system in the various groups of rats was assessed by measurements of plasma renin concen- 
Table I. Summary of Renal Cortical Microcirculation Studies

\begin{tabular}{|c|c|c|c|c|c|c|c|c|c|c|}
\hline & Body wt & Het & PUN & GFR & $\overline{\mathbf{A P}}$ & SNGFR & SNFF & $\mathrm{Q}_{A}$ & $\bar{P}_{\mathbf{G C}}$ & $P_{\mathrm{T}}$ \\
\hline & $g$ & $\mathrm{vol} / 100 \mathrm{ml}$ & $m g / 100 m l$ & $\mathrm{ml} / \mathrm{min}$ & $m m H g$ & $\mathrm{nl} / \mathrm{min}$ & & $n l / m i n$ & $m m H g$ & $\mathrm{mmHg}$ \\
\hline Group $1(n=8)$ & $250 \pm 3$ SEM & $40 \pm 1$ & $56 \pm 6$ & $0.60 \pm 0.07$ & $154 \pm 8$ & $73.0 \pm 6.0$ & $0.31 \pm 0.02$ & $234 \pm 16$ & $68 \pm 2$ & $18 \pm 1$ \\
\hline Group $2(n=8)$ & $248 \pm 4$ & $38 \pm 1$ & $55 \pm 3$ & $0.54 \pm 0.05$ & $107 \pm 2$ & $66.0 \pm 4.1$ & $0.28 \pm 0.01$ & $242 \pm 17$ & $53 \pm 1$ & $17 \pm 1$ \\
\hline Group $3(n=8)$ & $233 \pm 4$ & $36 \pm 1$ & $60 \pm 4$ & $0.61 \pm 0.08$ & $107 \pm 3$ & $63.6 \pm 5.2$ & $0.29 \pm 0.02$ & $224 \pm 18$ & $65 \pm 1$ & $16 \pm 1$ \\
\hline$P 1$ vs. 2 & NS & NS & NS & NS & $<0.005$ & NS & NS & NS & $<0.005$ & NS \\
\hline$P 2$ vs. 3 & $<0.020$ & NS & NS & NS & NS & NS & NS & NS & $<0.005$ & NS \\
\hline$P 1$ vs. 3 & $<0.010$ & $<0.010$ & NS & NS & $<0.005$ & NS & NS & NS & NS & NS \\
\hline
\end{tabular}

Abbreviations used in this table: $\pi_{\mathrm{A}}$, afferent arteriolar colloid osmotic pressure; $\pi_{\mathrm{E}}$, efferent arteriolar colloid osmotic pressure; $C_{\mathrm{A}}$, afferent arteriolar plasma protein concentration; $C_{\mathrm{E}}$, efferent arteriolar plasma protein concentration; $P_{\mathrm{E}}$, efferent arteriolar hydraulic pressure; $P_{\mathrm{T}}$, proximal tubule hydraulic pressure; PUN, plasma-urea-nitrogen concentration; $R_{\mathrm{A}}$, afferent arteriolar resistance; $R_{\mathrm{E}}$, efferent arteriolar resistance; $R_{\mathrm{T}}$, total arteriolar resistance $\left(R_{\mathrm{A}}+R_{\mathrm{T}}\right)$; and $\mathrm{SNFF}$, single nephron filtration fraction.

tration (Table II). Values for plasma renin concentration in untreated rats subjected to five-sixths nephrectomy averaged $3.8 \pm 0.7 \mathrm{ng} \mathrm{AI} / \mathrm{ml}$ per $\mathrm{h}$, a value which was lower on average than that measured in sham-operated control rats $(9.1 \pm 0.5 \mathrm{ng}$ $\mathrm{Al} / \mathrm{ml}$ per h) $(P<0.05)$. Inhibition of converting enzyme in rats with five-sixths nephrectomy treated with enalapril resulted in marked elevation of plasma renin concentration to an average of $194.5 \pm 28.0 \mathrm{ng} \mathrm{AI} / \mathrm{ml}$ per h $(P<0.05 \mathrm{vs}$. all other groups). In rats with five-sixths nephrectomy treated with triple drug therapy, values for plasma renin concentration averaged $21.9 \pm 2.5 \mathrm{ng} \mathrm{AI} / \mathrm{ml}$ per $\mathrm{h}$, a value significantly higher than those measured in sham-operated or untreated remnant kidney rats (both $P<0.05$ ).

Proteinuria. In the untreated group 4 rats, exposure to sustained glomerular hypertension was associated with glomerular injury, as manifested by increasing levels of proteinuria throughout the course of observation. As demonstrated in Fig. 2 , untreated rats excreted an average of $33 \pm 4 \mathrm{mg} / \mathrm{d}$ by the third week after ablation, and proteinuria increased further throughout the observation period. With only one-sixth the normal complement of glomeruli, remnant kidneys in these animals excreted $95 \pm 10 \mathrm{mg} / \mathrm{d}$ by $12 \mathrm{wk}$ after renal ablation. In contrast, control of systemic and glomerular hypertension in enalapril-treated group 5 rats was associated with considerably less proteinuria at the initial determination $(10 \pm 1 \mathrm{mg} / \mathrm{d}, P<0.005$ vs. group

Table II. Plasma Renin Concentrations and 24-h Urinary Sodium Excretion

\begin{tabular}{lllll}
\hline & SHAM & $\mathrm{NX}$ & $\mathrm{NX}+\mathrm{CEI}$ & $\mathrm{NX}+\mathrm{TRX}$ \\
\hline & $n=7$ & $n=7$ & $n=7$ & $n=7$ \\
$\begin{array}{c}\mathrm{PRC}, \mathrm{ng} \mathrm{AI} / \mathrm{ml} \\
\mathrm{per} \mathrm{h}\end{array}$ & $9.1 \pm 0.5^{*}$ & $3.8 \pm 0.7 \ddagger$ & $194.5 \pm 28.0^{*} \ddagger$ & $21.9 \pm 2.5^{*} \ddagger$ \\
$\begin{array}{c}\mathrm{U}_{\mathrm{Na}}^{\mathrm{V}} \\
\mathrm{mEq} / 24 \mathrm{~h}\end{array}$ & $1.28 \pm 0.07$ & $1.39 \pm 0.15$ & $1.50 \pm 0.15$ & $1.78 \pm 0.28$
\end{tabular}

Abbreviations used in this table: SHAM, sham-operated rats; NX, fivesixths nephrectomy; CEI, enalapril; TRX, reserpine, hydralazine, and hydrochlorothiazide; PRC, plasma renin concentration; AI, angioten$\sin \mathrm{I} ; \mathrm{U}_{\mathrm{Na}} \mathrm{V}$, urinary sodium excretion.

${ }^{*} P<0.05$ vs. NX.

$\ddagger P<0.05$ vs. SHAM.
4), and almost no increase in protein excretion thereafter. Despite equivalent control of systemic hypertension, the failure of triple drug therapy to control glomerular hypertension in group 6 rats allowed the development of progressive proteinuria. In this group, urinary protein excretion rates were lower than those seen in untreated group 4 rats at the initial determination ( 3 wk after ablation, Fig. 2), but thereafter rapidly rose to levels indistinguishable from those seen in the untreated group 4 rats. Despite continued control of systemic hypertension (Fig. 1), proteinuria in the triple drug-treated group 6 rats averaged $110 \pm 7$ $\mathrm{mg} / \mathrm{d}$ by 12 wk after five-sixths nephrectomy.

Structural alterations. At the end of the 12-wk observation period, untreated animals showed prominent and widespread glomerular alterations characterized by focal and segmental collapse of capillaries, hyaline deposition, and adhesion of the glomerular tuft to Bowman's capsule (Fig. $3 \mathrm{~A}$ ). These areas of collapse often contained vacuolated cells surrounded by basement membrane and matrix material. Focal and segmental obsolescence of the glomerular capillary tuft as described above was present in $22.5 \pm 4.4 \%$ of glomeruli in the untreated group 4 rats. In addition, occasional glomeruli in untreated animals showed microaneurysm formation identical in appearance to the lesions described previously in mineralocorticoid-salt hypertension (7). Epithelial cell abnormalities with increased numbers of lysosomes (reabsorption droplets) and cytoplasmic blebs were often observed. Occasional areas of tubule atrophy, interstitial fibrosis and mild chronic inflammation, and cast formation in distal tubules and ascending thick segments of the loop of Henle were observed in association with the glomerular abnormalities. Arteries and arterioles showed rare hypertrophic changes of their media with minimal hyaline deposition. In contrast, animals in group 5 treated with enalapril showed minimal structural alterations (Fig. $3 \mathrm{~B}$ ); the frequency of segmental glomerular lesions was reduced on average to $1.4 \pm 0.2 \%$, a value significantly lower than that seen in untreated group 4 animals $(P<0.01)$. Tubule, interstitial, and vascular alterations were virtually absent in this group. Despite equivalent control of systemic blood pressure, animals in group 6 receiving triple drug therapy (Fig. $3 C$ ) developed glomerular, tubule, and interstitial lesions similar in frequency and severity to untreated rats; the frequency of glomerular lesions in this group was $24.5 \pm 2.5 \%$, a value significantly higher than the average seen in enalapriltreated animals, $(P<0.01)$, but not different from that observed in the untreated group 4 rats. 
Table I. (Continued)

\begin{tabular}{|c|c|c|c|c|c|c|c|c|c|}
\hline$P_{\mathrm{E}}$ & $\overline{\Delta \mathrm{P}}$ & $C_{\mathrm{A}}$ & $C_{\mathrm{E}}$ & $\pi_{\mathrm{A}}$ & $\pi_{E}$ & $R_{\mathrm{A}} \times 10^{10}$ & $R_{\mathrm{E}} \times 10^{10}$ & $R_{\mathrm{T}} \times 10^{10}$ & $K_{f}$ \\
\hline$m m H g$ & $m m H g$ & $\mathrm{~g} / 100 \mathrm{ml}$ & $\mathrm{g} / 100 \mathrm{ml}$ & $m m H g$ & $m m H g$ & dyne $\cdot s \cdot \mathrm{cm}^{-s}$ & dyne $\cdot \mathrm{s} \cdot \mathrm{cm}^{-5}$ & dyne $\cdot s \cdot \mathrm{cm}^{-5}$ & $n l /(s \cdot m m H g)$ \\
\hline $21 \pm 1$ & $50 \pm 2$ & $5.5 \pm 0.1$ & $8.0 \pm 0.2$ & $18 \pm 1$ & $32 \pm 1$ & $1.78 \pm 0.18$ & $1.21 \pm 0.09$ & $2.98 \pm 0.20$ & $0.0492 \pm 0.0051$ \\
\hline $20 \pm 1$ & $36 \pm 1$ & $5.5 \pm 0.1$ & $7.6 \pm 0.1$ & $18 \pm 0.2$ & $29 \pm 1$ & $1.15 \pm 0.08$ & $0.84 \pm 0.07$ & $1.99 \pm 0.15$ & $0.0965 \pm 0.0133$ \\
\hline $21 \pm 1$ & $49 \pm 1$ & $5.7 \pm 0.1$ & $8.0 \pm 0.2$ & $19 \pm 0.4$ & $32 \pm 2$ & $1.00 \pm 0.10$ & $1.28 \pm 0.11$ & $2.28 \pm 0.18$ & $0.0462 \pm 0.0048$ \\
\hline NS & $<0.005$ & NS & NS & NS & NS & $<0.010$ & $<0.050$ & $<0.005$ & $<0.005$ \\
\hline NS & $<0.005$ & NS & NS & NS & NS & NS & $<0.010$ & NS & $<0.005$ \\
\hline NS & NS & NS & NS & NS & NS & $<0.005$ & NS & $<0.050$ & NS \\
\hline
\end{tabular}

\section{Discussion}

In the present study, monotherapy with enalapril, and triple drug therapy with reserpine, hydralazine, and hydrochlorothiazide were equally effective in controlling systemic hypertension despite the extensive reduction in renal mass. However, equivalent systemic blood pressure control in the two groups was associated with strikingly different glomerular hemodynamic consequences. In the untreated group 1 rats, afferent and efferent arteriolar vasodilatation resulted in elevation of the glomerular capillary plasma flow rate. While both afferent and efferent arteriolar resistances were much lower than those seen in normal rats (24), the proportionately greater reduction in afferent arteriolar resistance allowed elevation of the glomerular capillary hydraulic pressure. In the enalapril-treated group 2 rats, normalization of mean arterial pressure resulted in even further afferent arteriolar vasodilatation. However, the concomitant reduction in efferent arteriolar resistance offset the reduction in afferent arteriolar resistance, so that the glomerular capillary hydraulic pressure was reduced to near normal levels. In contrast, in group 3 rats treated with the triple drug regimen, the reduction in afferent arteriolar resistance associated with normalization of

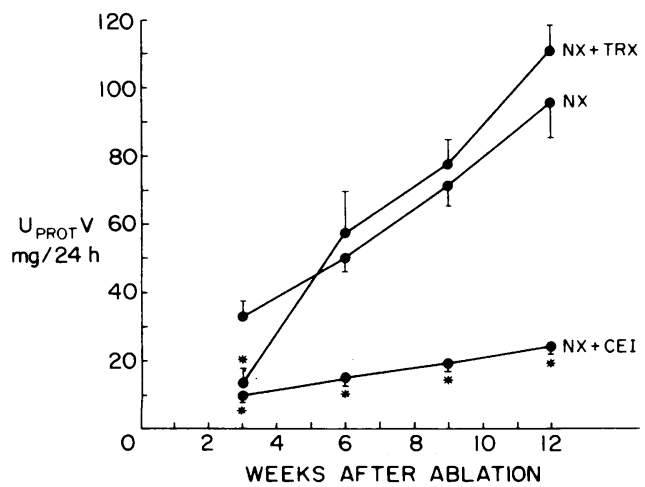

Figure 2. Urinary protein excretion rates. 24-h urinary protein excretion rates $\left(\mathrm{U}_{\mathrm{PROT}} \mathrm{V}\right)$ in rats with five-sixths nephrectomy. Untreated rats (group 4, NX) developed progressive proteinuria over the 12-wk course, while treatment with enalapril (group 5, NX + CEI) significantly limited proteinuria. Triple drug-treated rats (group 6, NX + TRX) had less proteinuria than untreated rats at the 3-wk time point, but comparable levels thereafter. Values are means \pm SEM. ${ }^{*} P$ $<0.05$ vs. group 4 at the same time point. systemic blood pressure was not accompanied by a proportional reduction in efferent arteriolar resistance. The combination of vasodilation and a diuretic, both of which are known to elevate plasma renin levels in humans $(25,26)$, preserved angiotensin II-induced efferent arteriolar tone in this group. Accordingly, the glomerular capillary hydraulic pressure was maintained at the same high level as was seen in the untreated group 1 rats. Therefore, control of systemic hypertension does not invariably result in control of intraglomerular hypertension, a finding recently reported in other experimental models as well $(13,14)$.

In all three groups of rats, intrarenal vasodilatation resulted in elevation of the glomerular capillary plasma flow rate, which contributed to the $\mathrm{SN}$ hyperfiltration. The renal vasodilatory response to enalapril may result from several potential mechanisms. Despite the subnormal plasma renin (and presumably angiotensin II) levels in the untreated rats, the remnant kidney exhibits enhanced responsiveness to angiotensin II (27), a hemodynamic effect which would be reversed by enalapril therapy. Alternatively, the antihypertensive and renal effects of enalapril may relate to the multiple non-renin-mediated actions of converting enzyme inhibitors (28). In the untreated group 1 and triple drug-treated group 3 rats, $\mathrm{SN}$ hyperfiltration was due to elevations in both the glomerular capillary plasma flow rate and the glomerular transcapillary hydraulic pressure gradient. In both of these groups, the $K_{\mathrm{f}}$ was lower than that seen in normal rats (24). While the mechanism of the decrease in $K_{\mathrm{f}}$ is not clear, an inverse relationship between $\overline{\Delta \mathrm{P}}$ and $K_{\mathrm{f}}$ has been demonstrated in a comprehensive analysis of the determinants of glomerular filtration (29). In the current setting, the reduction of $K_{\mathrm{f}}$ very likely represents damage to the glomerular capillary wall secondary to the high hydraulic pressures and flows within the glomerular capillary. In contrast, in the enalapril-treated group 2 rats, $K_{\mathrm{f}}$ was significantly higher than in the other two groups. This maintenance of $K_{\mathrm{f}}$ at normal levels presumably reflects preservation of glomerular capillary wall structural integrity in the presence of near-normal capillary hydraulic pressures, and preservation of $K_{\mathrm{f}}$ may contribute to long-term maintenance of SNGFR as well. In addition, the increase in $K_{\mathrm{f}}$ may reflect inhibition of the endogenous action of angiotensin II, a peptide known to lower $K_{\mathrm{f}}$ under a variety of physiological and pathophysiological circumstances $(30,31)$.

While renal function was not studied at the 12-wk time point, previous studies in our laboratory have shown that whole kidney GFR is still maintained as late as $18 \mathrm{wk}$ after ablation in untreated rats with five-sixths nephrectomy, despite more frequent glo- 

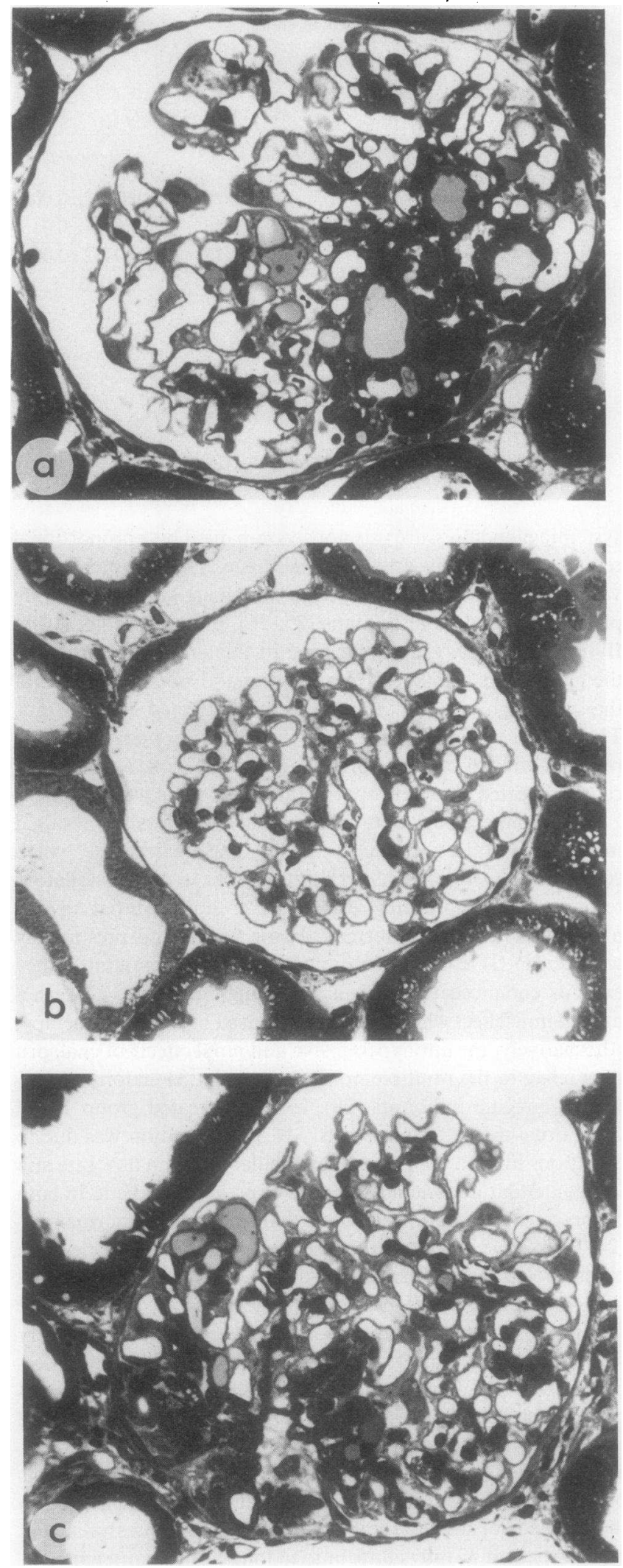

Figure 3. Light micrographs of renal cortex. Representative structural alterations seen in glomeruli from rats followed for $12 \mathrm{wk}$. (a) Untreated group 4, a characteristic area of segmental capillary collapse with hyaline deposition and adhesion of the tuft to Bowman's capsule is illustrated. (b) Enalapril-treated group 5. The structure of the glomerulus is well preserved. $(c)$ Triple drug therapy group 6 . A segmental lesion, similar to those seen in untreated animals is illustrated. (1$\mu \mathrm{m}$ thick epoxy sections stained with toluidine blue; 300 times). merular sclerosis. At this later time point, further nephron loss results in even further elevation of the SN plasma flow and filtration rates in the fewer remaining functional nephrons (32). Accordingly, it is reasonable to assume that whole kidney renal function would be maintained at 12 wk after ablation as well.

In untreated group 4 rats, systemic and glomerular hypertension were associated with progressive glomerular structural injury, as manifested by progressive proteinuria and the high frequency of glomerular sclerotic lesions. In enalapril-treated rats, control of systemic and glomerular hypertension was associated with limitation of progressive proteinuria and markedly fewer glomerular structural lesions. In the triple-drug treated rats, normalization of systemic blood pressure without control of glomerular hypertension afforded no protection against eventual glomerular structural injury. This latter finding provides a hemodynamic explanation for the finding, a decade ago, of Purkerson et al. (10) that normalization of systemic blood pressure with a similar regimen led to only modest reductions in proteinuria and glomerular sclerosis in rats with remnant kidneys. While the relationship between systemic and glomerular pressures may vary with experimental model and with antihypertensive regimen, preliminary reports suggest that triple drug therapy normalizes systemic pressure, but fails to lower glomerular capillary pressure and to lessen glomerular structural injury in rats with mineralocorticoid-induced hypertension (13) and in spontaneously hypertensive rats with ferritin-antiferritin glomerulonephritis (14).

Reduction in glomerular capillary hydraulic pressure may be achieved by several different hemodynamic mechanisms. In the spontaneously hypertensive rat, relative afferent arteriolar vasoconstriction prevents transmission of high systemic pressures to the glomerular capillary network, thereby preventing increases in glomerular capillary hydraulic pressure $(33,34)$. When this relative afferent vasoconstriction is abolished by uninephrectomy (35) or induction of diabetes (36), glomerular capillary hydraulic pressure increases. In our remnant kidney rats, and in the hyperfiltering kidneys of normotensive diabetic rats (8), reduction of efferent arteriolar resistance with enalapril therapy results in reduction of $\overline{\Delta \mathbf{P}}$. Whereas afferent arteriolar vasodilatation allows transmission of systemic pressure to the glomerular capillary network, in both of the latter models the concomitant reduction in efferent arteriolar resistance effectively prevents the rise in $\overline{\Delta \mathbf{P}}$.

Taken together, these observations suggest that glomerular capillary hypertension plays a pivotal role in the glomerular destruction which eventuates in diverse renal diseases characterized by glomerular hyperfiltration. Though direct measurements have not been made, reduction of glomerular capillary hypertension may well prove to be the mechanism whereby antihypertensive therapy (37) or dietary protein restriction (38) affords protection in immune complex-mediated glomerular diseases as well. Conversely, failure to control glomerular capillary hypertension may explain the failure of adequate systemic blood pressure control to prevent glomerular injury in rats with renal ablation (10) and mineralocorticoid-induced hypertension (13). While intrarenal hemodynamics have not been studied, it is tempting to speculate that the inclusion of a $\beta$-blocker, which might prevent renin release and thus elevation of efferent arteriolar resistance and maintenance of high $\overline{\Delta \mathbf{P}}$, explains the reported beneficial effect of antihypertensive therapy in spontaneously hypertensive rats with experimental diabetes (39).

The current study raises several important questions concerning the role of control of systemic hypertension in the man- 
agement of patients with progressive renal disease. Recent studies have provided encouraging evidence that control of systemic blood pressure may slow the progressive course of renal disease due to diabetes mellitus $(40,41)$, essential hypertension (42), and intrinsic renal disease (43-44). We would suggest, however, that more specific knowledge of the intrarenal hemodynamic effects of the numerous antihypertensive drugs available to the clinician is needed before a beneficial renal outcome may be confidently predicted. In particular, we must be aware of the potential intrarenal consequences of blood pressure reduction in those patients with clinically apparent reduction in functioning nephron number, since these patients are at highest risk of further hemodynamically mediated glomerular injury.

\section{Acknowledgements}

Donna McDermott provided expert secretarial assistance.

This study was supported by U. S. Public Health Service Grant AM35930 and by a grant from Merck, Sharp \& Dohme. Dr. Anderson is the recipient of an Individual National Research Service Award of the National Institutes of Health (SF32AM07206).

\section{References}

1. Hayslett, J. P. 1979. Functional adaptation to reduction in renal mass. Physiol. Rev. 59:137-164.

2. Deen, W. M., D. A Maddox, C. R. Robertson, and B. M. Brenner. 1974. Dynamics of glomerular ultrafiltration in the rat. VII. Response to reduced renal mass. Am. J. Physiol. 227:556-562.

3. Hostetter, T. H., J. L. Olson, H. G. Rennke, M. A. Venkatachalam, and B. M. Brenner. 1981. Hyperfiltration in remnant nephrons: a potentially adverse response to renal ablation. Am. J. Physiol. 241:F85F93.

4. Anderson, S., T. W. Meyer, H. G. Rennke, and B. M. Brenner. 1985. Control of glomerular hypertension limits glomerular injury in rats with reduced renal mass. J. Clin. Invest. 76:612-619.

5. Hostetter, T. H., T. W. Meyer, H. G. Rennke, and B. M. Brenner. 1986. Chronic effects of dietary protein on renal structure and function in the rat with intact and reduced renal mass. Kidney Int. In press.

6. Zatz, R., T. W. Meyer, H. G. Rennke, and Barry M. Brenner. 1985. Predominance of hemodynamic rather than metabolic factors in the pathogenesis of diabetic glomerulopathy. Proc. Natl. Acad. Sci. USA. 82:5963-5967.

7. Dworkin, L. D., T. H. Hostetter, H. G. Rennke, and B. M. Brenner. 1984. Hemodynamic basis for glomerular injury in rats with desoxycorticosterone-salt hypertension. J. Clin. Invest. 73:1448-1461.

8. Zatz, R., B. R. Dunn, T. W. Meyer, S. Anderson, H. G. Rennke, and B. M. Brenner. 1986. Prevention of diabetic glomerulopathy by pharmacological amelioration of glomerular capillary hypertension. $J$. Clin. Invest. 77:1925-1930.

9. Azar, S., M. A. Johnson, J. Iwai, L. Bruno, and L. Tobian. 1978. Single nephron dynamics in "post-salt" rats with chronic hypertension. J. Lab. Clin. Med. 91:156-166.

10. Purkerson, M. L., P. E. Hoffsten, and S. Klahr. 1976. Pathogenesis of the glomerulopathy associated with renal infarction in rats. Kidney Int. 9:407-417.

11. Neugarten, J., B. Kaminetsky, H. Feiner, R. G. Schacht, D. T. Liu, and D. S. Baldwin. 1985. Nephrotoxic serum nephritis with hypertension: amelioration by antihypertensive therapy. Kidney Int. 28:135139.

12. Raij, L., X. Chiou, R. Owens, and B. Wrigley. 1985. Therapeutic implications of hypertension induced glomerular injury. Comparison of enalapril and a combination of hydralazine, reserpine and hydrochlorothiazide in an experimental model. Am. J. Med. 79(3C):37-41.

13. Dworkin, L. D., H. D. Feiner, and J. Randazzo. 1985. Evidence for hemodynamically mediated glomerular injury despite antihyperten- sive therapy in rats with desoxycorticosterone salt hypertension. Kidney Int. 27:189a. (Abstr.).

14. Azar, S., W. Keane, and L. Raij. 1985. Antihypertensive therapy in nephritic spontaneously hypertensive rats: effects on nephron dynamics and morphology. Kidney Int. 27:187a. (Abstr.).

15. Pfeffer, J. M., M. A. Pfeffer, and E. D. Frohlich. 1971. Validity of an indirect tailcuff method for determining systolic arterial pressure in unanesthetized normotensive and spontaneously hypertensive rats. J. Lab. Clin. Med. 78:957-962.

16. Maddox, D. A., D. C. Price, and F. C. Rector, Jr. 1977. Effects of surgery on plasma volume and salt and water excretion in rats. Am. J. Physiol. 233:F600-F606.

17. Deen, W. M., J. L. Troy, C. R. Robertson, and B. M. Brenner. 1973. Dynamics of glomerular ultrafiltration in the rat. IV. Determination of the ultrafiltration coefficient. J. Clin. Invest. 52:1500-1508.

18. Vurek, G. C., and S. E. Pegram. 1966. Fluorometric method for the determination of nanogram quantities of inulin. Anal. Biochem. 16: 409-419.

19. Führ, J., J. Kaczmarczyk, and C. D. Krüttgen. 1955. Eine einfache colorimetrische Methode zur Inulinbestimmung für Nieren-clearanceUntersuchungen bei Stoffwechselgesunden und Diabetikern. Klin. Wochenschr. 33:729-730.

20. Viets, J. W., W. M. Deen, J. L. Troy, and B. M. Brenner. 1978. Determination of serum protein concentration in nanoliter blood samples using florescamine or o-phthaldehyde. Anal. Biochem. 88:513-521.

21. Davidsohn, L., and J. B. Henry. 1969. Clinical Diagnosis by Laboratory Methods. 14th ed. W. B. Saunders Co., Philadelphia. 48.

22. Wallenstein, S., C. L. Zucker, and J. L. Fleiss. 1980. Some statistical methods useful in circulation research. Circ. Res. 47:1-9.

23. Glantz, S. A. 1981. Primer of Biostatistics. McGraw-Hill Book Co., Inc. New York. 292-299.

24. Ichikawa, I., D. A. Maddox, M. G. Cogan, and B. M. Brenner. 1978. Dynamics of glomerular ultrafiltration in euvolemic Munich-Wistar rats. Renal Physiol. 1:121-131.

25. Alhenc-Gelas, F., P. Plouin, M. Ducrocq, P. Corvol, and J. Menard. 1978. Comparison of the antihypertensive and hormonal effects of a cardioselective beta-blocker, acebutolol, and diuretics in essential hypertension. Am. J. Med. 64:1005-1012.

26. Pettinger, W. A., and H. C. Mitchell. 1975. Renin release, saralasin and the vasodilator-beta-blocker drug interaction in man. $N$. Engl. J. Med. 292:1214-1216.

27. Hostetter, T. H., and L. F. Mares. 1984. Hemodynamics of the remnant nephron. Response to acute arterial hypertension. Clin. Res. 32:450a. (Abstr.).

28. Zusman, R. M. 1984. Renin- and non-renin-mediated antihypertensive actions of converting enzyme inhibitors. Kidney Int. 25:969983.

29. Tucker, B. J., and R. C. Blantz. 1981. Effects of glomerular filtration dynamics on the glomerular permeability coefficient. Am. J. Physiol. 240:F245-F254.

30. Blantz, R. C., K. S. Konnen, and B. J. Tucker. 1976. Angiotensin II effects upon the glomerular microcirculation and ultrafiltration coefficient of the rat. J. Clin. Invest. 57:419-434.

31. Schor, N., I. Ichikawa, and B. M. Brenner. 1980. Glomerular adaptation to chronic dietary salt restriction or excess. Am. J. Physiol. 248:F428-F436.

32. Meyer, T. W., S. Anderson, H. G. Rennke, and B. M. Brenner. 1985. Control of glomerular hypertension retards progression of established glomerular injury in rats with renal ablation. Kidney Int. 27:247a. (Abstr.).

33. Azar, S., M. A. Johnson, J. Scheinman, L. Bruno, and L. Tobian. 1979. Regulation of glomerular capillary pressure and filtration rate in young Kyoto hypertensive rats. Clin. Sci. (Lond.). 56:203-209.

34. Arendshorst, W. J., and W. H. Beierwaltes. 1979. Renal and nephron hemodynamics in spontaneously hypertensive rats. Am. J. Physiol. 236:F246-F251.

35. Dworkin, L. D., and H. D. Feiner. 1986. Glomerular injury in uninephrectomized spontaneously hypertensive rats. A consequence of glomerular capillary hypertension. J. Clin. Invest. 77:797-809. 
36. Bank, N., R. Klose, and H. S. Aynedjian. 1985. Glomerular pressure in rats with diabetes and hypertension. Kidney Int. 27:241a. (Abstr.).

37. Okuda, S., K. Onoyama, S. Fujimi, Y. Oh, K. Nomoto, and T. Omae. 1983. Influence of hypertension on the progression of experimental autologous immune complex nephritis. J. Lab. Clin. Med. 101:461-471.

38. Neugarten, J., H. D. Feiner, R. G. Schacht, and D. S. Baldwin. 1983. Amelioration of experimental glomerulonephritis by dietary protein restriction. Kidney Int. 24:595-601.

39. Rabkin, R., J. Petersen, J. Kitaji, B. Marck, W. Murphy, and E. E. Muirhead. 1984. Effect of antihypertensive therapy on the kidney in spontaneously hypertensive rats with diabetes. Kidney Int. 25:205a. (Abstr.)

40. Mogensen, C. E. 1981. Long-term antihypertensive treatment (over six years) inhibiting the progression of diabetic nephropathy. Acta Endocrinol. Suppl. 242:31-32.
41. Parving, H.-H., A. R. Andersen, U. M. Smidt, J. S. Christiansen, B. Oxenboll, and P. A. Svendsen. 1983. Diabetic nephropathy and arterial hypertension: the effect of antihypertensive treatment. Diabetes. 32(Suppl. 2):83-87.

42. Bauer, J. H. 1984. Role of angiotensin converting enzyme inhibitors in essential and renal hypertension. Am. J. Med. 77:43-51.

43. Oldrizzi, L., C. Rugiu, E. Valvo, A. Lupo, C. Loschavio, L. Gammaro, N. Tessitore, A. Fabris, G. Panzetta, and G. Maschio. 1985. Progression of renal failure in patients with renal disease of diverse etiology on protein-restricted diet. Kidney Int. 27:553-557.

44. Branca, G. F., A. Satta, R. Faedda, G. Soggia, N. A. Olmeo, R. Vacca, and E. Bartoli. 1984. Effects of blood pressure control on the progression of renal insufficiency in chronic renal failure. Panminerva Med. 25:215-218. 